\title{
Adaptive Technologies for Individuals with Visual Impairments: Scholarly and Consumer Perspectives
}

\section{Debra Mann}

\begin{abstract}
Adaptive technologies allow people with visual impairments to access information, but problems surrounding access and availability to these technologies exist. Scholarly literature and reports by organizations such as the Canadian National Institute for the Blind and the Canadian Library Association have recognized and discussed these problems and strategies to overcome them. Libraries are among the organizations that are making adaptive technologies more widely available to consumers. A number of adaptive technologies are discussed.
\end{abstract}

\begin{abstract}
About the Author(s): Debra Mann is enrolled in the first year of the Master of Library and Information Studies program at Dalhousie University's School of Information Management. Debra spent several years working with adults and children with exceptional needs and is interested in exploring the information needs of individuals with visual, cognitive and communication impairments. The original version of this paper was submitted in November, 2005 for LIBS 5500, Information in Society.
\end{abstract}




\section{Introduction}

Individuals with visual impairments face numerous obstacles, but one of the largest is access to information. Traditional information packages such as books or computer screens do not fit their needs and must be adapted in order to be effectively accessed. Adaptive technologies have been created to bridge this gap, but studies by scholars and organizations show that the full range of these technologies are not being widely utilized. This paper discusses the scholarship on adaptive technologies by information professionals and organizations, and follows with an exploration of the availability of these technologies to the average visually impaired consumer. Please note that adaptive technologies are given brief descriptions within the text; please see Appendix A for a more detailed glossary.

\section{Discussion}

The scholarship on adaptive technologies is diverse, and includes articles on the types of adaptive technologies that exist, the guidelines that have been created to facilitate their development and use, and the gaps in their provision that have been identified by scholars, librarians and consumers. The following is a very brief selection of literature that touches on the subject of accessibility.

\section{Scholarly perspectives}

Kerscher (2001) provided a summary of adaptive technologies for reading text that are available to people with visual impairments. He outlined the evolution of "talking books\&quot; as an alternative to Braille books, the traditional way of interpreting text with groups of small bumps that represented characters. Talking books were available in an open reel tape format, two-, four- and six-track formats, and cassette formats. These technologies provided audio reading of text in a linear fashion, which meant that if a person wanted to hear the text out of sequence, as a student using a textbook might, he/she would have to move through the text using forward and reverse mechanisms. This was time consuming, as it is difficult to pinpoint the location of a single page of text on a reel of tape. More recently, organizations and libraries for the blind came together to push for a "next generation of talking books", which led to the formation of the DAISY (digital accessible information system) Consortium, a group dedicated to creating digital-based talking books and readers. The digital technology used in DAISY readers allows people with visual impairments to listen to text in a linear fashion, skip through text to chapters and specific pages, adjust the speed of audio output, and place bookmarks in the text (Beaumont and Judge, 2005).

Kerscher does not discuss technologies that allow people with visual impairment to access the Internet, nor does he comment on the quality and availability of adaptive technologies, but much of the recent scholarship on adaptive technologies is related to these two problems. Turner (2002) identified a report done in the UK by the Library \& Information Statistics Unit of 
Loughborough University. This report was based on a telephone and interview-based survey of just under 600 visually impaired individuals who were asked to rate the performance of library services available to them, such as the National Library for the Blind and the Royal National Institute for the Blind. The study found that consumers tended to prefer cassette-based audio tapes to other forms of audio technology, and that respondents were often not aware of the services that were available to them. Turner also indicated that though legislation such as the Disability Discrimination Act ensured a receptive environment for implementation of programs to service the visually impaired population, few libraries had specific policies to address their needs.

In 2000, Valenza identified a number of adaptive technologies that she felt were emerging and worthy of library consideration. These included digital books, web-based Braille services, where screen content is transmitted to a Braille reader, and screen readers, which transmit text on a computer screen into spoken text. Yet she also identified major drawbacks to those technologies that assisted visually impaired library consumers from fully participating. For example, she discussed her frustration while watching a patron use a screen reader. The design of the web site the patron was attempting to access did not allow for clear and linear reading of the text, but instead skipped back and forth between frames, graphics and sidebars. She indicated that there were easy ways libraries could evaluate the accessibility of their own web-based services. One example is Bobby, a tool that allows users to input the URL of a web site and generate a list of the elements in the site that present problems for visually impaired consumers. Five years later, Westin (2005) identified similar problems still occurring today related to web access for the visually impaired and others with disabilities, arguing that this population will increase dramatically in the US (and, by extension, Canada) as the Baby Boomer generation ages. He identified a key barrier for those seeking access to web-based technology:

In the case of the Web, the adaptive technological problems can be particularly vexing because of its stateless, two-tiered (i.e., client/server) architecture. That is, the adaptive technologies reside on the client side, but the Web content can be designed and served with no knowledge of how the AT is configured, or even that such is being used. Consequently, Web content that is designed without regard for such technologies can render the content useless for the end user. (p. iii)

Westin mentioned ways in which Windows can be configured to allow for better access for those with limited vision, such as setting preferences for font and size, but indicated that graphics may still be unavailable to users. He called for better textual information to be embedded within the code of web sites to allow for aural cues to be transmitted through screen readers, and encouraged businesses to embrace compliance to government accessibility guidelines as part of good business practice. 
Westin also discussed the Web Accessibility Initiative (WAI) of the World Wide Web Consortium (W3C). This group advocates for Web accessibility and has developed guidelines and techniques to assist both web and software developers in creating web content for people with a range of accessibility issues. It claims to "[pursue] accessibility of the Web through five primary activities:

1. Ensuring that core technologies of the Web support accessibility

2. Developing guidelines for Web content, user agents, and authoring tools

3. Facilitating development of evaluation and repair tools for accessibility

4. Conducting education and outreach

5. Coordinating with research and development that can affect future accessibility of the Web (Web Accessibility Initiative, 2005a)

The WAI web site includes practical instructions to web site and software developers on how to achieve compliance with its guidelines. Each guideline includes a checkpoint, which is a practical example of the guideline at work, and a priority rating, which indicates whether a developer must, should or may implement the guideline in question (Web Accessibility Initiative, 2005b). This set of guidelines has the potential to effectively resolve the conflict identified by Westin.

Based on the recommendations of the $\mathrm{W} 3 \mathrm{C}$ and US government regulations, specifically section 508 of the American Disabilities Act, Byerley and Chambers (2002) evaluated two popular library tools. After citing some rather disheartening studies that indicated US academic and public libraries were ineffective at providing adequate web-based services to clients with visual impairments, they used two screen reader technologies to attempt to navigate Periodical Abstracts, a ProQuest product, and ASAP, a Gale Group product. The researchers tested the products themselves and then had two visually impaired individuals (a university student and a consultant) test the products. The results indicated several areas for improvement but were largely positive, noting that both companies are aware of compliance issues. A similar study of e-journals (Coonin, 2002), however, found a much lower level of compliance to section 508 and the WAI. The study evaluated 12 popular e-journal aggregators such as JSTOR, Kluwer Online and Science Direct using the Bobby system, and found numerous problems such as lack of alternative text in hot spots or images, and inability to read image PDFs with a screen reader.

\section{Organizational perspectives}

Organizations such as the Canadian National Institute for the Blind (CNIB) and the Canadian Library Association (CLA) are aware of these same gaps in service presented in the scholarly 
literature. This awareness is reflected in organizational policy and advocacy activity, which aims to increase access to adaptive technologies for those with visual impairments.

The CNIB is a national organization that provides services for people with a range of visual impairments. It is a not for profit organization that depends on volunteers and donations to allow them to provide "rehabilitation, library accessibility, mobility and other special technological programs and services" for Canadians with visual impairments (CNIB, 2005d). It identifies its seven core services as library services, counselling and referral, rehabilitation teaching, orientation and mobility, vision rehabilitation, technical aids and career development and employment (CNIB, 2005e). The CNIB also offers unique and comprehensive programs specifically for individuals who are both deaf and blind.

The CNIB Library web site points out that "Canada is the only G8 country that does not fund library services for people who are blind or visually impaired" (CNIB, 2005a). To that end, the organization has recently released a report entitled "An Unequal Playing Field: Report on the Needs of People who are Blind or Visually Impaired Living in Canada" (CNIB, 2005b). The report echoes the findings of Turner in that many people in Canada do not access adaptive technologies because they are not able to get information about them. After transportation, adaptive technologies were the next greatest unmet need identified by people with visual impairments polled for the report (CNIB, 2005b, p.74). Over 80 percent of people in this study used adaptive technologies, but upon closer inspection the percentage of people using technologies other than cassette tapes drops dramatically to approximately 20 percent, especially among seniors. High-tech products like DAISY readers and adaptive computer equipment are largely not used because of the costs associated with them (CNIB, 2005b, p.7783).

The Canadian Library Association also recently released a report on the needs of visually impaired individuals. Entitled "Opening the Book: A Strategy for a National Network for Equitable Library Service for Canadians with Print Disabilities" (CLA, 2005), the CLA report pointed out that Canada has no national legislation aimed at national library services for people with visual impairments (p. 2). The report stated that ten percent of the Canadian population is print disabled in some way; this statistic includes people with visual impairments. This report considers all people with print disabilities, including those who cannot physically hold a book or are cognitively impaired. Because of this, the CLA singled out the CNIB for its contributions for people with visual impairments, but also pointed out that less than five percent of printed information in Canada is available in alternate formats (CLA, 2005, p.19). The CLA referred to a report released by the Council on Access to

Information for Print-Disabled Canadians, formed by National Librarian Roch Carriere, entitled "Fulfilling the Promise: The Report of the Task Force on Access to Information for PrintDisabled Canadians," which pointed out that public libraries are excellent hubs for access to special materials for people with print disabilities. It stated that many public libraries were 
already providing products and services for this population, and made numerous recommendations to the government to make these universally accessible (Library and Archives Canada, 2000).

\section{Adaptive technologies: opportunities for consumers}

From an academic perspective, there is ample awareness of the challenges regarding access to information and access to adaptive technologies for people with visual impairments. The larger issue, however, is how this awareness impacts the experiences of visually impaired consumers. The following is a discussion of the practical availability of the adaptive technologies and opportunities identified by scholars and organizations.

\section{The Canadian National Institute for the Blind}

As might be expected, the most comprehensive provider of adaptive technologies to visually impaired consumers is the CNIB. It distributes technical aids to visually impaired Canadians anywhere in the country through its "Products for Independence" catalogue and Technical Aids Service stores across the country. These services collect product information from manufacturers of adaptive technologies, from medical aids to games to watches to recording equipment, into one resource so that consumers can compare prices and features. The stores, which are located in every CNIB office, offer a selection of the products featured in the catalogues (CNIB, 2005g). Products are suitable for individuals with varying degrees of visual impairment; clocks and watches, for instance, are available in large print formats, with talking features, or in Braille. In addition to products that assist clients in their activities of daily living, the catalogue and stores offer numerous products that allow access to print and audio information, such as Braille embossing paper, magnifiers and DAISY players (CNIB, 2005f).

The CNIB's Library for the Blind provides Braille books, audio books, digital audio books and descriptive video (video with an audio track that describes the image) to its clients. The collection includes material for adults and children. It is presently pursuing a project entitled "That All May Read", which will result in the transformation of its collection of materials from analog to digital technology, thereby increasing service levels and availability to its clients (CNIB, 2005a).

The library's web site presents impressive statistics in regards to its collection. It offers 4,000 DAISY CDs, 13,000 Braille titles, 18,000 Braille music scores and music books, 2,500 PrintBraille titles, 630 described videos, 9 DAISY magazines and 28 Braille magazines. In addition, it has access to thousands of online titles in digital audio, e-text and e-Braille, numerous newspapers and digital media material, and reference databases. The library has developed a partnership with the National Library for the Blind in the United Kingdom which allows clients to access its holdings as well (CNIB, 2005c). 
Other useful services provided by the library are listed on the various pages of its web site, such as telephone access to listen to favourite magazines, reader advisory services, and the Skyclub Internet discussion group. It also has a music library that contains Braille copies of instrumental and vocal musical scores, operatic librettos and books on music. The children's library features a kid's reading club, Braille reading competitions and the Spinoza Talking Bear program, which provides talking book machines in the form of teddy bears to children. Even the web site itself served as an excellent example of accessibility. In form and appearance, it conformed to the suggestions given in the scholarly literature regarding clarity and ease of use for individuals using screen readers.

The CNIB library catalogue provides users with the option of searching its catalogue and catalogues of other libraries that had significant collections of materials for people with visual impairments. The search screen features keyword and browse searching and has a very clear, uncomplicated interface suitable for use by individuals employing screen readers. The digital library catalogue features a number of national and local newspapers, popular magazines and reference works (CNIB, 2005h).

\section{Public libraries}

The CNIB provides access to its library collection and services to individuals anywhere in Canada, but local libraries often carry materials that are suitable for use by people with visual impairments as well. The Halifax Public Library, for example, has a section in its web site devoted to people with access issues. In it, they specify that they provide "talking books...descriptive and closed-captioned videos and large-print books" as well as TDD Numbers at their reference desks (Halifax Public Library, 2005a).

The library's online catalogue provides two access points for people with visual impairments. The interface links to a Large Print and Special Format section that divides resources into large print fiction and non-fiction, books on tape, and books on CD. In addition to this, clients can enter the word "Braille" into the regular catalogue to find books in Braille format (Halifax Public Library, 2005b).

Provision of service to people with visual impairments in public libraries varies by location. Libraries in small, remote or rural centres may have a more limited collection of audio or Braille books on site. Such libraries may also choose to concentrate on the acquisition of audio material over Braille, perhaps as a way of attracting the growing population of people who enjoy audio books and do not have visual impairments, or who have print disabilities other than visual impairment. This is not necessarily a major barrier, however, because visually impaired clients have access to interlibrary loans through their public libraries, which allows them to access the resources of libraries across the country and around the world, in addition to the aforementioned CNIB Library collection.

\section{Adaptive Technology Resource Centre}


The Adaptive Technology Resource Centre (ATRC) at the University of Toronto is an excellent resource for both individuals and libraries that are interested in the kinds of technologies available to people with visual impairments (University of Toronto, n.d. a). The organization provides a number of services from consultation to research and development. One particularly useful service is the Vision Technology Service, available to individuals who are "unable to perform every day age-related visual tasks in spite of conventional medical, surgical and/or routine refractive interventions (such as glasses)" (University of Toronto, n.d. d). Clients are assessed for the level of service they will require, and then introduced to the types of technologies that will be of assistance to them. The technologies include screen readers and magnifiers, portable note taking devices, and closed circuit television. The ATRC also includes a service to assist in workplace training/retraining.

An especially helpful page on the ATRC web site is the technical glossary, which features links to pages that explain adaptive technologies and provide links to product distributors (University of Toronto, n.d. b). Products include haptic devices, which provide tactile sensation as feedback (as in the case of a computer mouse that allows you to 'feel' the output on a computer screen), refreshable Braille displays that turn lines of text from a computer monitor into Braille, and special accessibility functions for Linux users. It even includes extreme examples like neural interface devices. This technology, though still in development, promises to be extremely helpful to people with multiple disabilities. It turns the electric signals generated by the human body into signals that can be interpreted by computers. For example, a small probe surgically implanted into the brain or body of an individual can translate eye movements or brain waves into digital signals, which can then be read by special software and used to manipulate a computer or electronic device (University of Toronto, n.d. c).

The ATRC presents an incredible breadth of products, but in addition it also includes information on how to access funding for these aids. The problem of cost is a common theme in the scholarship on this topic; adaptive technology can be prohibitively expensive and, according to a number of the previously cited reports and articles, this presents a very real and quantifiable barrier to access.

\section{Conclusion}

Barriers to access of information continue to exist for people with visual impairments, but recent scholarship indicates that a number of these barriers have been identified, and potential solutions suggested. Organizations such as the CNIB, the University of Toronto's Adaptive Technology Research Centre, the CLA and libraries across Canada are creating policies, advocating and providing adaptive technologies to bridge the gap in access and services to people with visual impairments. From new technologies such as DAISY books, to products that adapt existing information packages into appropriate formats such as screen readers, to libraries that cater to the needs of print disabled users, the visually impaired community has the potential to access information with increasing ease. It is hoped that the recommendations 
of the CLA, LAC and CNIB will increase accessibility, both through an increase in materials and technologies to service visually impaired clients, and through increases in funding for their production and dissemination.

\section{Appendix A: technical glossary}

The following material is taken from the excellent technical glossary provided by the University of Toronto's Adaptive Technology Resources Centre (see Reference list). I have only included a selection of adaptive technologies that relate specifically to visual impairments.

Alternative Keyboards: Alternative keyboard layouts and other enhancements allow people who experience difficulty with conventional keyboard designs to use computers. The products available range from keyguards that prevent accidental key activation, to alternative keyboards with differing layouts, sizes, etc. for people who have specific needs, to alternative input systems which require other means/methods of getting information into a computer.

Braille Embosser and Text to Braille Conversion: A Braille Embosser is a hardware device for "printing" a hard copy of a text document in Braille. A Braille translation software program is required to translate the text from the computer into Braille. Most Braille translation software programs can translate material into several grades or versions of Braille. There is also a new Music Braille software program as well as scanning software to scan Braille into a computer and have it displayed or translated into text.

Closed Circuit Television (CCTV): A Closed Circuit TeleVision (CCTV) is a video magnification system consisting of a video screen interfaced with a video camera. Video magnification is achieved in two ways - the electronic conversion from the small camera imager to the larger display screen and the optical effect of the cameras zoom lens. The stand mounted CCTVs can be configured with either television receivers, video monitors, or computer monitors. The CCTV system provides high contrast, inverse video display, gray scale, false colours, natural colours, and/or control of contrast level and brightness.

Haptic Devices: The word "haptic" means "of or relating to or proceeding from the sense of touch" (http://www.dict.org). A haptic interface is a device which allows a user to interact with a computer by receiving tactile feedback. This feedback is achieved by applying a degree of opposing force to the user along the $x, y$, and $z$ axes. These devices can be used by people with disabilities or people who learn best through tactile or kinesthetic experiences. The use of haptic devices that once were cost prohibitive but now are incorporated into mainstream devices such as the iFeel Mouse and the IFeel Mouseman, promote inclusion and acceptance of "adaptive" technology into the "daily computer experience" of people with and without disabilities.

Optical Character Recognition (OCR): Optical character recognition (OCR) is the process of converting an image of text, such as a scanned paper document or electronic fax file, into 
computer-editable text. The text in an image is not editable: the letters are made of tiny dots (pixels) that together form a picture of text. During OCR, the software analyzes an image and converts the pictures of the characters to editable text based on the patterns of the pixels in the image. After OCR, you can export the converted text and use it with a variety of wordprocessing, page layout and spreadsheet applications. OCR also enables screen readers and refreshable braille displays to read the text contained in images.

Refreshable Braille Displays: Refreshable Braille Displays are electronic devices that are used to read text that a computer sends to the monitor. The device is connected to the computer by a serial cable and produces Braille output on the Braille display. Refreshable Braille displays only read one line of text at a time. These displays generally include directional keys which allow the user to navigate through a document. Larger displays (80 cells) also include a cursor routing function. Each cell contains eight small pins, allowing eight dot computer Braille rather than the six dot Braille we are used to seeing.

Screen Magnifiers: Screen magnification software are used by people with visual disabilities to access information on a computers screen. The software enlarges the information on the screen by pre-determined incremental factor [for example, $1 x$ magnification, $2 x$ magnification, $3 x$ magnification, etc,]. Magnification programs run simultaneously and seamlessly with the computer's operating system and applications. Most screen magnification software has the flexibility to magnify the full screen, parts of the screen or provide a magnifying glass view of the area around the cursor or pointer. These programs also often allow for inverted colours, enhanced pointer viewing and tracking options.

Screen Readers and Talking Browsers: A Screen Reader is the commonly used name for Voice Output Technology used. Screen readers are used to replace the visual display traditionally viewed on a monitor for those with visual disabilities. Hardware and software produce synthesized voice output for text displayed on the computer screen, as well as for keystrokes entered on the keyboard. Talking browsers use the same technology as screen reading software, but the reading functions are limited to Internet use. 


\section{References}

Jane Beaumont and Chris Judge, 30 October 2005. "Adaptive library technologies for the visually impaired". Brown bag lunch lecture.

Suzanne L. Byerley and M.B. Chambers, 2002. "Accessiblity and usability of web-based library databases for non-visual users," Library Hi Tech, volume 20, number 2, pp. 169-179.

Canadian Library Association, 2005. "Opening the book: a strategy for a national network for equitable library service for Canadians with print disabilities," at http://www.cla.ca/issues/nnels_final_august2005.pdf, accessed 27 November 2005.

Canadian National Institute of the Blind, 2005a. "About the CNIB library for the blind," at http://www.cnib.ca/library/general_information/about_lib.htm, accessed 27 November 2005.

Canadian National Institute of the Blind, 2005b. "An unequal playing field: a report on the needs of people who are blind or visually impaired livingin Canada," at http://cnib.ca/eng/publications/needsreport/UnequalPlayingField_ENG_FINALWORD.pdf, accessed 27 November 2005.

Canadian National Institute of the Blind, 2005c. "CNIB library for the blind reader services," at http://www.cnib.ca/library/for_clients/about.htm, accessed 27 November 2005.

CanadianNational Institute of the Blind, 2005d.\&nbsp; "Media centre: who we are, what we do," at http://www.cnib.ca/eng/media-centre/journalists/who_what.htm, accessed 27 November 2005.

Canadian National Institute of the Blind, 2005e. "Media centre: services snapshot," at http://www.cnib.ca/eng/media-centre/journalists/snapshot.htm, accessed 27 November 2005.

Canadian National Institute of the Blind, 2005f "Products for independence catalogue," at http://www.cnib.ca/tech_aids/catalogue, accessed 27 November 2005.

Canadian National Institute of the Blind, 2005g. "Technical aids," at http://www.cnib.ca/tech_aids/index.htm, accessed 27 November 2005.

Canadian National Institute of the Blind, 2005h. "VisuCAT," at http://visucat.cnib.ca:8000/<br>LOGIN:sessionid=0:next=html/databases.html:bad=html/authof ail.html:entitylanginit=FALSE:entitylang=eng:autho=eng/GUEST:password=GUEST:entitynoPa tron=FALSE,accessed 27 November 2005.

Bryna Coonin, 2002. "Establishing accessibility for e-journals: A suggested approach," Library Hi Tech, volume 20, number 2, pp. 207-221. 
Halifax Public Library, 2005a. "Access for all," at http://www.halifaxpubliclibraries.ca/services/accessall.html, accessed 27 November 2005.

Halifax Public Library, 2005b. "Catalogue Search," at http://catalogue.halifaxpubliclibraries.ca/,accessed 27 November 2005.

George Kerscher, 2001. "DAISY consortium: Information technology for the world's blind and print-disabled population - past, present, and into the future", Library Hi Tech, volume 19, number 1, pp.11.

Library and Archives Canada, Council on Access to Information for Print-Disabled Canadians, 2000. "Fulfilling the promise: the report of the task force on access to information for printdisabled Canadians," at http://www.collectionscanada.ca/accessinfo/s36-200e.html">http://www.collectionscanada.ca/accessinfo/s36-200-e.html, accessed 27 November 2005.

Richard Turner, 2002. "Out of sight but not out of mind: Visually impaired people's perspectives of library and information services", New Library World, volume 103, number 6, pp. 237-239.

University of Toronto, n.d. a. "Adaptive technology resource centre," at http://www.utoronto.ca/atrc/sitemap.html, accessed 27 November 2005.

University of Toronto, n.d. b. "Adaptive technology resource centre technical glossary," at http://www.utoronto.ca/atrc/reference/tech/techgloss.html, accessed 27 November 2005.

University of Toronto, n.d. c. "Adaptive technology resource centre technical glossary: neural interface devices," at http://www.utoronto.ca/atrc/reference/tech/neuralinterface.html", accessed 27 November 2005.

University of Toronto, n.d. d. "Adaptive technology resource centre vision technology service," at http://www.utoronto.ca/atrc/service/vts.html, accessed 27 November 2005.\&nbsp;

Joyce Kasman Valenza, 2000. "Surfing blind," Library Journal, Fall 2000, pp. 34-36.

Web Accessibility Initiative, 2005a. "WAI mission and organization," at http://www.w3.org/WAl/about.html, accessed 27 November 2005.

Web Accessibility Initiative, 2005b. "Web Content Accessibility Guidelines (WCAG) overview," at http://www.w3.org/WAl/intro/wcag.php, accessed 27 November 2005.

Stu Westin, 2005. "Cutting curbs on the information highway: Embracing adaptive technology to broaden the web," Journal of Organizational and End User Computing, volume 17, number 3, pp. i-x. 